\title{
Pendampingan Penerbitan dan Penyiapan Akreditasi Nasional bagi Pengelola Jurnal Bidang Pengabdian kepada Masyarakat Perguruan Tinggi di Kota Semarang
}

\author{
Parmin $^{1}$, Stephani Diah Pamelasari², Endah Fitriani Rahayu ${ }^{3}$, Aji Saputra ${ }^{4}$ \\ Universitas Negeri Semarang $1,2,3,4$ \\ parmin@mail.unnes.ac.id ${ }^{1}$, stephanipamelasari@mail.unnes.ac.id ${ }^{2}$, endah_danis@mail.unnes.ac.id ${ }^{3}$, \\ putraji8901@students.unnes.ac.id ${ }^{4}$
}

\begin{abstract}
Activities with service journal managers as research targets aim to increase managers' knowledge about management and journal articles' substance quality. Manager's knowledge which is the focus of activities, refers to the accreditation assessment of national journals. The main target of community service activities is the manager of the university service journal in Semarang. The method of mentoring activities is carried out online, divided into two forms: for management and article substance. Evaluation of activities was carried out through analysis of the value of pre-test and post-test questions on journal management and article substance and questionnaire analysis of participants' feedback. The average pre-test score is 65, and the post-test is 84, indicating an increase in knowledge on the target activities. From the mentoring in publishing service journals that have been carried out, the journal manager (the target of the activity) has had broader knowledge about the management and substance of the article. The accreditation simulation in the mentoring process has provided an authentic experience for managers to be more prepared to propose accreditation and reaccreditation of service journals.
\end{abstract}

Keywords: mentoring; accreditation; service journal.

\begin{abstract}
Abstrak
Kegiatan dengan sasaran para pengelola jurnal pengabdian bertujuan untuk meningkatkan pengetahuan pengelola tentang tata kelola dan kualitas substansi artikel jurnal. Pengetahuan pengelola yang menjadi fokus kegiatan mengacu dari penilaian akreditasi jurnal nasional. Sasaran utama kegiatan pengabdian kepada masyarakat adalah pengelola jurnal pengabdian perguruan tinggi di Kota Semarang. Metode kegiatan pendampingan yang dilakukan secara online atau daring. Tahapan kegiatan dibagi dalam dua bentuk pendampingan untuk manajemen dan substansi artikel. Evaluasi kegiatan dilakukan melalui analisis nilai soal pre-test dan post-test tentang manajemen jurnal dan substansi artikel serta analisis angket minat balikan peserta. Rata-rata nilai pre-test 65 dan post-test 84 artinya ada peningkatan pengetahuan pada sasaran kegiatan. Pendampingan penerbitan jurnal pengabdian telah dilakukan, pengelola jurnal sasaran kegiatan telah memiliki pengetahuan yang lebih luas tentang manajemen dan substansi artikel. Simulasi akreditasi dalam proses pendampingan telah memberikan pengalaman nyata bagi para pengelola sehingga lebih siap untuk mengusulkan akreditasi dan reakreditasi jurnal pengabdian.
\end{abstract}

Kata Kunci: pendampingan; akreditasi; jurnal pengabdian. 


\section{A. PENDAhuluan}

Pengabdian kepada masyarakat yang dilakukan dosen, tenaga pendidikan, dan mahasiswa di perguruan tinggi menghasilkan laporan kegiatan dan produk pengabdian. Laporan pengabdian tidak sebatas dalam bentuk laporan yang dikumpulkan menjadi arsip akademik tetapi dipublikasikan melalui seminar maupun publikasi di jurnal. Setiap laporan pengabdian masyarakat yang akan dipublis melalui jurnal maka dibutuhkan penyusunan artikel standar akreditasi jurnal. Hasil pengabdian masyarakat lebih bermanfaat apabila dipublikasikan melalui jurnal dari pada sebatas laporan kegiatan. Hasil pengabdian yang dipublikasikan melalui jurnal berpotensi dibaca dan dikaji oleh pembaca atau masyarakat sehingga terbuka peluang metode kegiatan dapat didesiminasikan secara lebih luas. Publikasi membutuhkan pengetahuan pengelolaan jurnal dan penulisan artikel. Dosen dalam menunjang tugas tri dharma pendidikan perlu memiliki pengetahuan tentang standar artikel yang berkualitas (Jatmiko, et al. 2015; Nafilatur \& Muhammad, 2016).

Jurnal untuk publikasi artikel hasil pengabdian kepada masyarakat memiliki spesifikasi khusus yaitu jurnal pengabdian masyarakat. Jurnal pengabdian khusus mempublis artikel hasil pengabdian yang dilakukan akademisi di perguruan tinggi dan pelaku kegiatan pengabdian dari berbagai instansi. Jurnal pengabdian memiliki kekhususan dari sistematika penyajian artikel, memiliki kesamaan dengan sistematika laporan kegiatan pengabdian. Kualitas artikel di jurnal pengabdian masyarakat ditentukan dari ketepatan pemilihan metode kegiatan dan hasil kegiatan berdampak pada masyarakat sasaran. Artikel berkualitas tidak sebatas meringkas laporan tetapi menekankan pada dampak kegiatan bagi sasaran (Adhikara, $e t$ al. 2014; Rahmawati, 2018; Ginanjar, 2019).

Artikel pengabdian yang berkualitas menyajikan hasil kegiatan yang secara nyata berdampak pada masyarakat sasaran. Hasil yang berdampak nyata dikemas dalam artikel pengabdian yang memenuhi standar penulisan artikel mulai dari etika publikasi dan kualitas konten artikel (Ananta, et al. 2016; Talvin \& Widjaja, 2021). Pengabdian masyarakat bersifat aplikatif karena menerapkan hasil-hasil penelitian langsung pada masyarakat sasaran. Apabila hasil kegiatan berdampak besar bagi masyarakat maka jika tidak dipublikasikan melalui jurnal, tidak diketahui oleh khalayak umum secara lebih luas. Hasil pengabdian yang dipublikasikan melalui jurnal diharapkan hasil-hasil yang telah diperoleh diadopsi masyarakat di luar sasaran.

Ketertarikan para pengabdi untuk mempublikasikan hasil pengabdian kepada masyarakat melalui jurnal mendapat respon dari pengelola perguruan tinggi termasuk yang ada di Kota Semarang. Jumlah perguruan tinggi di Kota Semarang pada tahun 2021 sebanyak 30 dengan rincian status 4 kedinasan, 4 negeri, dan 22 swasta yang diperoleh dari website L2DIKTI Wilayah VI.

Publikasi menjadi bagian penting dalam persaingan perguruan tinggi karena menentukan budaya akademik, penerapan pengetahuan dan teknologi, dan reputasi lembaga. Jurnal pengabdian tidak sebatas kebutuhan dosen dan tenaga pendidik tetapi memiliki peran penting untuk mendapatkan kepercayaan masyarakat terhadap perguruan tinggi. Hasil analisis jumlah perguruan tinggi yang tidak sebanding dengan jumlah jurnal pengabdian yang dimiliki, sangat dibutuhkan penambahan jurnal baru di bidang pengabdian.

Analisis data dari Science and Technology Index 
(https://sinta.ristekbrin.go.id/) jurnal pengabdian masyarakat yang dimiliki perguruan tinggi di kota semarang yang telah terakreditasi nasional 5 sedangkan hasil penelusuran ke perguruan tinggi yang belum terakreditasi ada 16 jurnal dan ada beberapa jurnal yang penyiapan terbit pertama. Jumlah jurnal pengabdian yang ada jauh dari kebutuhan, artinya masih sangat terbatas dibandingkan dengan jumlah akademisi di Kota Semarang. Hasil analisis di SINTA dan sumber data dari L2Dikti Wilayah VI, jumlah jurnal pengabdian tidak sebanyak jumlah jurnal di bidang penelitian. Temuan dari analisis kebutuhan bahwa dalam 3 tahun terakhir, minat pengabdi yang mempublikasikan di jurnal pengabdian mengalami peningkatan. Keterbatasan jumlah jurnal yang menjadi kendala utama sehingga tidak dapat menampung sebagian besar artikel. Ketertarikan menerbitkan artikel pengabdian diperkuat dengan aturan dalam Pedoman Operasional Penilaian Angka Kredit Kenaikan Jabatan Akademik/Pangkat Dosen yang menghargai nilai 5 untuk setiap pengabdian yang dipublikasi di jurnal. Sementara untuk angka kredit pengabdian yang sebatas laporan kegiatan nilai 1 . Pengakuan artikel menjadi salah satu faktor pendorong penulis untuk mmepublikasikan artikel di jurnal (Isa, et al. 2016; Ismail \& Elihami, 2019).

Jumlah jurnal pengabdian yang terbatas berpotensi berdampak pada terbatasnya jumlah artikel yang dapat diterbitkan. Kondisi ini dikhawatirkan menurunkan minat pengabdi untuk mempublikasi hasil kegiatan dalam bentuk artikel jurnal. Keterbatasan jumlah jurnal menjadikan artikel yang kualitas kurang baik tidak mampu bersaing yang akhirnya tidak dapat dipublis. Kualitas artikel ditentukan dari pengalaman menulis dan mempublikasikan karya ilmiah sehingga dikhawatirkan pengabdi pemula sulit bersaing. Dampak dari sulit bersaing bagi pengabdi yang baru dapat berakibat menurunkan minat membuat artikel dari kegiatan pengabdian yang telah dilakukan. Keterbatasan jumlah jurnal ditambahkan dengan minimnya jurnal pengabdian yang sudah terakreditasi nasional. Analisis kebutuhan menemukan jumlah yang belum terakreditasi lebih banyak dari yang sudah terakreditasi. Ada beberapa jurnal yang sudah terbit lebih dari 5 tahun tetapi belum terakreditasi karena ada persyaratan minimal belum terpenuhi. Persyaratan minimal yang belum terpenuhi diantaranya sudah memiliki p-ISSN tetapi belum memiliki e-ISSN (RistekBrin, 2019). Beberapa jurnal gagal terbit minimal 2 kali dalam satu tahun bahkan ada jurnal yang sudah tidak terbit lebih dari 2 tahun. Persyaratan minimal memiliki DOI pada beberapa jurnal terutama di perguruan tinggi swasta yang ada di Kota Semarang belum terpenuhi.

Analisis kebutuhan telah dilakukan dengan mengungkap permasalahan dari pihak pengelola jurnal pengabdian masyarakat di perguruan tinggi yang ada di Kota Semarang. Terdapat 3 temuan permasalahan yang dialami para pengelola jurnal yaitu; (1) Kurang pengetahuan tentang kebijakan akreditasi nasional jurnal di bidang pengabdian masyarakat; (2) Keterbatasan wawasan tentang tata kelola jurnal pengabdian masyarakat; dan (3) Strategi kenaikan level akreditasi untuk jurnal pengabdian masyarakat. Permasalahan yang dihadapi para pengelola jurnal menjadi salah satu penyebab keterbatasan jurnal pengabdian masyarakat yang diterbitkan perguruan tinggi di Kota Semarang.

Permasalahan yang telah ditemukan dalam tata kelola jurnal pengabdian masyarakat secara khusus pada perguruan tinggi di Kota Semarang harus segera diatasi. Permasalahan yang ada tidak saja dari pengelola jurnal tetapi penulis dan secara lebih luas pada pengelola perguruan tinggi. Pengetahuan tata kelola jurnal pengabdian 
yang kurang bahkan diakui beberapa pengelola sangat terbatas, berpotensi dapat menyulitkan dalam proses penerbitan artikel yang berkualitas. Informasi tentang akreditasi jurnal khusus bidang pengabdian masyarakat sangat dibutuhkan oleh para pengelola jurnal. Bagi sebagian kecil jurnal yang sudah terakreditasi masih di level bawah antara SINTA 6 sampai SINTA 3, membutuhkan strategi menaikkan level agar dapat terakreditasi di SINTA yang lebih tinggi.

Tujuan pengabdian kepada masyarakat dengan sasaran pengelola jurnal pengabdian untuk; meningkatkan pengetahuan pengelola tentang tata kelola dan kualitas substansi artikel jurnal sesuai kriteria akreditasi nasional. Solusi yang ditawarkan untuk menyelesaikan kedua masalah utama yaitu: (1) jumlah jurnal bidang pengabdian kepada masyarakat masih jauh dari kebutuhan atau kurang; dan (2) jumlah jurnal yang telah ada masih sangat terbatas yang sudah terakreditasi nasional. Kedua masalah dapat diatasi melalui kegiatan pendampingan penerbitan dan pendampingan persiapan akreditasi jurnal. Pendampingan penerbitan dilakukan pada pengelola pengabdian kepada masyarakat di perguruan tinggi. Penerbitan jurnal baru mendesak untuk dilakukan karena kebutuhan pengabdi untuk mempublikasikan artikel tidak terpenuhi akibat keterbatasan jumlah jurnal. Keterbatasan kapasitas karena jumlah artikel yang terbit di setiap jurnal memiliki batas maksimal sehingga solusi terbaik dan tercepat adalah menerbitkan jurnal baru.

Jurnal pengabdian yang telah terbit karena masih sangat terbatas yang berstatus terakreditasi maka akan dilakukan pendampingan bagi para pengelola jurnal. Pendampingan penyiapan akreditasi jurnal dilakukan untuk memberikan wawasan penilaian akreditasi yang terbaru dan dilanjutkan dengan simulasi akreditasi.
Jurnal yang belum terakreditasi akan disimulasikan dengan instrumen penilaian akreditasi sehingga pengelola dapat menggunakan sebagai refleksi dan perbaikan pengelolaan. Penyiapan akreditasi bagi yang sudah terakreditasi juga perlu dilakukan sehingga dapat mempersiapkan pengusulan reakreditasi jurnal untuk mendapatkan level di SINTA yang lebih tinggi.

\section{B. PELAKSAAAN DAN METODE}

Pengelola kegiatan pengabdian masyarakat pada perguruan tinggi di Kota Semarang membutuhkan pengetahuan tentang penerbitan jurnal yang sesuai dengan panduan tata kelola jurnal pengabdian sesuai kriteria akreditasi. Metode kegiatan dilakukan secara online untuk sesi pendampingan manajemen dan substansi artikel. Sasaran kegiatan pengabdian kepada masyarakat adalah pengelola kegiatan pengabdian masyarakat dan pengelola jurnal pengabdian perguruan tinggi di Kota Semarang. Tahapan kegiatan dibagi dalam dua bentuk pendampingan yaitu manajemen dan substansi artikel. Secara rinci tahapan persiapan, pelaksanaan, dan evaluasi kegiatan sebagai berikut. Soal pre-test dan post-test sama, menanyakan tentang manajemen jurnal dan substansi artikel. Jumlah butir soal 20 dengan bentuk pilihan ganda dengan 4 pilihan.

Kegiatan dilaksanakan melalui tahapan koordinasi tim dosen pengabdian masyarakat dengan pimpinan L2Dikti Wilayah VI; perizinan dan undangan bagi pengelola jurnal pengabdian kepada masyarakat perguruan tinggi di Kota Semarang; penyusunan jadwal pelaksanaan pembimbingan dan pendampingan tata kelola jurnal pengabdian; penyiapan pengukuran pengetahuan awal sasaran untuk menjadi bahan evaluasi keefektifan pendampingan yang akan dilakukan; dan 
penyiapan fasilitas pertemuan online atau daring.

Memberikan pre-test bagi peserta untuk menilai pengetahuan awal peserta tentang penerbitan jurnal pengabdian. Menyajikan materi tentang penerbitan jurnal pengabdian yang standar akreditasi jurnal nasional. Pendampingan penyiapan penerbitan jurnal pengabdian baru setiap pengelola pengabdian dari perguruan tinggi sasaran. Target jurnal baru yang diterbitkan setiap perguruan tinggi minimal 1 jurnal baru. Pendampingan pendaftaran e-ISSN jurnal pengabdian baru. Memberikan posttest bagi peserta untuk menilai pengetahuan akhir peserta tentang penerbitan jurnal pengabdian. Menyajikan materi tentang strategi akreditasi nasional jurnal pengabdian.

Pendampingan penyiapan akreditasi dan reakreditasi jurnal pengabdian. Target jurnal baru yang disiapkan akreditasi setiap perguruan tinggi minimal 1 jurnal. Evaluasi pelaksanaan kegiatan pengabdian masyarakat, secara rinci mekanisme evaluasi melalui analisis Nilai pre-test dan post-test peserta pendampingan dan peserta mengisi angket yang bersifat tertutup dengan 4 pilihan jawaban yaitu; sangat setuju (skor 4), setuju (skor 3), kurang setuju (skor 2), dan tidak setuju (skor 1).

\section{HASIL DAN PEMBAHASAN}

Tim pengabdian kepada masyarakat dari FMIPA Universitas Negeri Semarang telah melakukan pertemuan secara daring dengan aplikasi melalui https://zoom.us/. Perguruan tinggi di Kota Semarang yang telah mengirimkan pengelola jurnal pengabdian yaitu; Universitas Negeri Semarang, STIEPARI Semarang, Universitas Wahid Hasim, Universitas 17 Agustus 1945 Semarang, Universitas Dian Nuswantoro, Politeknik Bumi Akpelni, Universitas PGRI Semarang, Universitas
Muhammadiyah Semarang, dan hadir beberapa perguruan tinggi mitra di sekitar Kota Semarang. Jumlah pengelola jurnal yang hadir sebanyak 42 orang. Kegiatan diawali dengan melakukan pre-test pengetahuan pengelola terhadap standar penilaian akreditasi jurnal. Pendamping mengawali dengan menyajikan data tentang masih sangat sedikit jurnal di bidang pengabdian terutama di Kota Semarang yang terakreditasi nasional.

Perbandingan pengetahuan peserta dari data pre-test dan post-test pada Tabel 1.

Tabel 1. Perbandingan pre-test dan post-test pengelola jurnal pengabdian

\begin{tabular}{lcc}
\hline & Pre-Test & Post-Test \\
\hline $\begin{array}{l}\text { Nilai } \\
\text { tertinggi }\end{array}$ & 68 & 88 \\
$\begin{array}{l}\text { Nilai } \\
\text { terendah }\end{array}$ & 64 & 81 \\
Rata-rata & 65 & 84 \\
\hline Kategori & Cukup & Tinggi \\
\hline
\end{tabular}

Peserta diberikan pemaparan tentang standar penilaian akreditasi dari aspek manajemen dan substansi artikel. Berbagai tips dibagikan tentang standar penilaian akreditasi jurnal pengabdian dengan contohcontoh beberapa jurnal pengabdian yang telah sukses memperoleh peringkat akreditasi di Sinta 2. Antusiasme peserta sangat baik dengan banyaknya bahan diskusi yang tersampaikan mulai dari tahapan untuk menerbitkan jurnal pengabdian baru, menyiapkan jurnal untuk akreditasi, dan strategi agar jurnal yang telah terakreditasi naik peringkat. Persyaratan minimal akreditasi jurnal menjadi topik yang menarik, mulai bagaimana mendapatkan eISSN, DOI, menerbitkan artikel yang standar akreditasi, dan membuat link dengan berbagai organisasi profesi. 
Berbagai pertanyaan dari peserta pendampingan direkap pada Tabel 2.

Tabel 2. Pertanyaan dan jawaban proses pendampingan

Pertanyaan
Bagaimana cara mencari editor
dan reviewer sesuai
karakteristik jurnal pengabdian?

Jawaban

Ada beberapa cara yang dapat dilakukan; (1) menelusuri penulis di jurnal pengabdian yang sudah terakreditasi, bersurat elektronik (email) menawarkan ke penulis yang telah memiliki rekam jejak mempublis artikel pengabdian; (2) melalui jaringan organisasi profesi menawarkan pada orang yang dipercaya dan kompeten untuk menjadi editor maupun reviewer; dan (3) jaringan pertemanan yang ada dengan dosen dari berbagai perguruan tinggi.

Bagaimana cara mendapatkan (1) Kontrol sistem jurnal secara baik untuk merespon artikel pengabdian masyarakat yang berkualitas? artikel yang masuk melalui OJS; (2) Menawarkan bagi para penulis melalui website jurnal atau website lembaga; (3) Pengelola jurnal menggunakan media sosial untuk mempromosikan jurnal; dan (4) Mengundang para penulis untuk mensubmit artikel.

Bagaimana proses pengelolaan artikel yang standar dari submit sampai publis? Strategi apa yang harus dilakukan agar jurnal pengabdian lebih diminati penulis?

Bagaimana tahapan menyiapkan jurnal pengabdian untuk didaftarkan akreditasi nasional?

Bagaimana cara agar jurnal pengabdian naik level di SINTA?
Alur pengelolaan artikel mulai dari submit, review, cek similaritas, apabila terbit berbahasa Inggris ada tahap proofread, accepted dan publis.

Publikasikan jurnal melalui website, media sosial, dan dalam pertemuan ilmiah agar lebih dikenal para penulis.

Penuhi syarat minimal untuk pengusulan akreditasi, kemudian simulasikan penilaian jurnal sebelum di daftarkan akreditasi.

Tata kelola jurnal sudah sehat dengan berfungsinya editor dan reviewer, manajemen yang standar, dan kualitas artikel yang baik.
Minat balikan peserta setelah dilakukan pendampingan dilakukan melalui angket yang bersifat tertutup. Hasil isian angket terdapat pada Tabel 3. 
Tabel 3. Minat Balikan Peserta Pendampingan

\begin{tabular}{|c|c|c|c|c|}
\hline \multirow{2}{*}{ Pernyataan } & \multicolumn{4}{|c|}{ Jawaban Responden } \\
\hline & Sangat Setuju & Setuju & Kurang Setuju & Tidak Setuju \\
\hline $\begin{array}{l}\text { Pengelola jurnal pengabdian } \\
\text { membutuhkan } \\
\text { pendampingan }\end{array}$ & 33 & 9 & - & - \\
\hline $\begin{array}{l}\text { Pendampingan bagi } \\
\text { pengelola jurnal pengabdian } \\
\text { perlu dilakukan secara } \\
\text { berkelanjutan }\end{array}$ & 30 & 12 & - & - \\
\hline $\begin{array}{l}\text { Pengetahuan tentang } \\
\text { manajemen pengelolaan } \\
\text { jurnal pengabdian semakin } \\
\text { banyak setelah } \\
\text { pendampingan }\end{array}$ & 28 & 14 & - & - \\
\hline $\begin{array}{l}\text { Pengetahuan tentang } \\
\text { kualitas substansi artikel } \\
\text { jurnal pengabdian semakin } \\
\text { banyak setelah } \\
\text { pendampingan }\end{array}$ & 31 & 11 & - & - \\
\hline $\begin{array}{l}\text { Sebelum jurnal pengabdian } \\
\text { diajukan akreditasi perlu } \\
\text { dilakukan pendampingan }\end{array}$ & 37 & 5 & - & - \\
\hline
\end{tabular}

Kegiatan pendampingan telah dipublikasikan melalui media nasional dan website perguruan tinggi. Publikasi di media nasional pada Gambar 1.

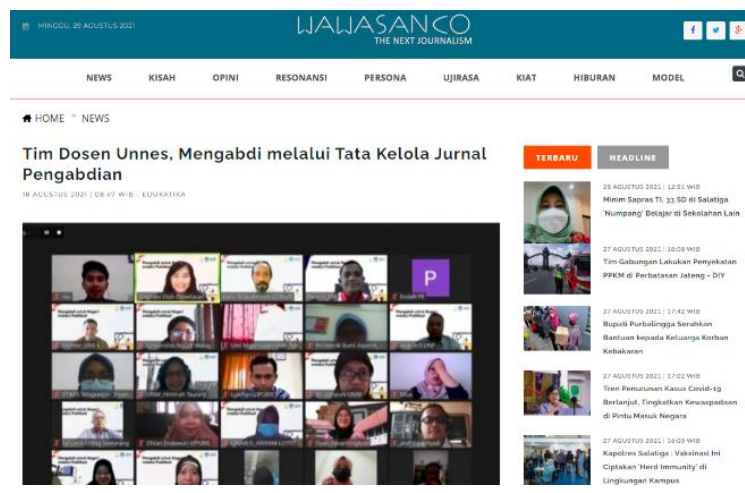

Gambar 1. Publikasi Kegiatan Pengabdian kepada Masyarakat di Media Nasional

Publikasi melalui website internal perguruan tinggi pada Gambar 2.

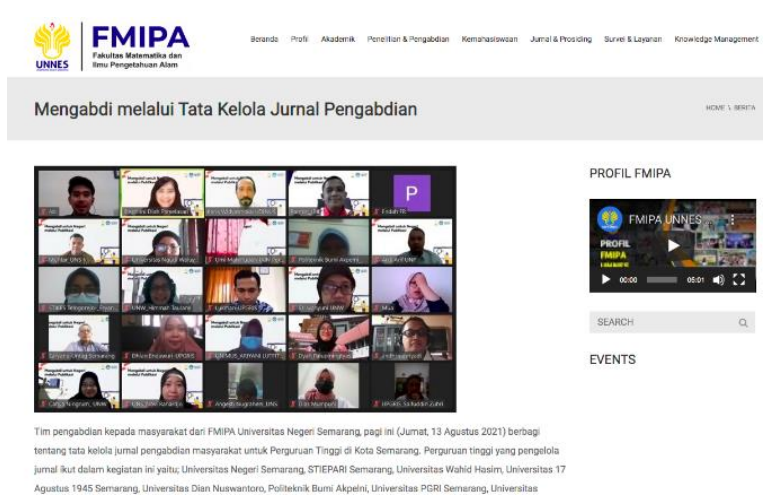

Gambar 2. Publikasi Kegiatan Pengabdian kepada Masyarakat di Website Perguruan Tinggi

Pendampingan bagi pengelola jurnal pengabdian kepada masyarakat menjadi bagian dari solusi agar mahasiswa, tenaga kependidikan, dan dosen di perguruan tinggi terdorong untuk melakukan publikasi hasil 
pengabdian masyarakat. Pengetahuan pengelola jurnal sebelum kegiatan termasuk dalam kategori cukup, artinya layak sebagai pengelola jurnal pengabdian. Setelah kegiatan pendampingan melalui pemberian materi standar penilaian akreditasi dan simulasi review artikel untuk jurnal pengabdian, pengetahuan peserta mengalami peningkatan dengan kategori tinggi dengan skor rata-rata 84 . Peningkatan pengetahuan peserta sasaran pengabdian yang diukur berdasarkan kenaikan nilai posttest dari nilai pre-test, menunjukkan materi yang diberikan dapat dipahami peserta (Yuli \& Sugianti, 2019; Tundjungsari \& Suhaeri, 2018). Peningkatan pengetahuan tentang tata kelola jurnal pengabdian menjadi tahapan penting dalam proses perbaikan manajemen jurnal dan substansi artikel.

Analisis terhadap jurnal pengabdian oleh peserta pendampingan ditemukan kekurangan pada aspek manajemen. Kekurangan mendasar ada beberapa jurnal belum memiliki e-ISSN tetapi memiliki pISSN sehingga belum memenuhi persyaratan minimal untuk diajukan akreditasi. Proses pendampingan diprioritaskan untuk menyiapkan dokumen usulan e-ISSN, mekanisme pengusulan dan strategi agar segera terbit. Sebagian besar kekurangan jurnal ada pada keterbatasan editor dan reviewer. Pendampingan memberikan stategi mendapatkan editor dan reviewer di bidang pengabdian masyarakat. Peserta pendampingan telah memahami bahwa jumlah dan sebaran editor dan reviewer menjadi aspek penilaian akreditasi jurnal. Mukhlisah, et al. (2021) proses review artikel yang ketat pada bagian kualitas substansi menjadikan kualitas artikel semakin baik. Reviewer internal perguruan tinggi penerbit perlu dibatasi untuk memberikan ruang bagi orang di luar lembaga penerbit.
Peserta pendampingan diminta mengunduh satu artikel yang telah terbit di masing-masing jurnal pengabdian yang dikelola. Artikel dianalisis dari mulai judul sampai dengan referensi untuk menemukan kelemahan dan kekuatan artikel. Simulasi akreditasi menemukan kelemahan mendasar pada kualitas isi substansi artikel, kelemahan utama pada bagian pendahuluan yang lemah dalam menyajikan rasionalitas kegiatan dengan dukungan analisis kebutuhan yang kuat. Kurang dukungan data dan fakta pada bagian analisis situasi di bagian pendahuluan, menyebabkan penilaian pada bagian pendahuluan masih kurang. Kelemahan ditemukan pada bagian metode yang sebagian besar sangat sederhana. Pengabdian masih dominan berbentuk pelatihan yang belum tampak dampak nyata bagi sasaran. Pengalaman pengelola mensimulasikan akreditasi jurnal menjadi pengetahuan penting untuk proses review artikel-artikel yang akan diterbitkan. Widoarjo, et al. (2020) \& Junandi (2018) kualitas jurnal pengabdian ditentukan dari kualitas substansi artikel.

Pendampingan dilakukan juga pada beberapa jurnal yang baru akan terbit. Proses menyiapkan dokumen dan kelengkapan persyaratan menjadi penekanan pada jurnaljurnal baru. Persyaratan minimal penerbitan jurnal baru yang meliputi; website, pengelola, standar tata kelola, jumlah minimal artikel, kualitas artikel, dan e-ISSN. Standar jurnal yang akan diterbitkan telah disesuaikan dengan aspek penilaian akreditasi. Pengelola jurnal dari hasil angket minat balikan, merasakan manfaat dari program pendampingan karena ada penambahan pengetahuan pada tata kelola jurnal. Berbagai kelemahan kualitas substansi artikel juga dapat diketahui sesuai kriteria penilaian akreditasi jurnal. Krismayani (2021) sitasi suatu karya tulis ilmiah ditentukan dari kebermanfaatan temuan. Sasaran kegiatan berkeinginan setiap 
jurnal yang akan diusulkan akreditasi untuk mendapatkan pendampingan dari pakar sehingga memiliki potensi besar mendapatkan status akreditasi.

Jurnal bidang pengabdian masyarakat masih jauh dari harapan karena antara jumlah penulis dan artikel belum seimbang dengan jurnal yang tersedia. Perhatian bagi jurnal bidang pengabdian juga tidak sebaik jurnal bidang penelitian. Komunitas pengelola jurnal bidang pengabdian juga masih langka sehingga tata kelola jurnal di bidang ini termasuk lambat. Perhatian yang lebih serius dari pengelola perguruan tinggi dan komunitas jurnal dibutuhkan agar lebih banyak lagi artikel pengabdian kepada masyarakat yang dapat dipublikasikan. Metode kegiatan pemberdayaan kepada masyarakat melalui pengabdian banyak yang belum tersampaikan pada publik, diharapkan melalui penerbitan di jurnal pengabdian dapat semakin banyak hasilhasil pengabdian yang dapat diadopsi secara lebih luas. Pendampingan mulai dari proses pendirian jurnal, penerbitan, pengusulan akreditasi, dan reakreditasi pada para pengelola jurnal pengabdian harus dilakukan secara berkelanjutan.

\section{PENUTUP}

\section{Simpulan}

Pendampingan penerbitan jurnal pengabdian telah dilakukan, pengelola jurnal sasaran kegiatan telah memiliki pengetahuan yang lebih luas tentang manajemen dan substansi artikel. Simulasi akreditasi dalam proses pendampingan telah memberikan pengalaman nyata bagi para pengelola sehingga lebih siap untuk mengusulkan akreditasi dan reakreditasi jurnal pengabdian. Dampak nyata yang diperoleh dari hasil pendampingan maka diperlukan proses-proses pendampingan lanjutan sehingga jurnal bidang pengabdian akan semakin banyak yang terakreditasi nasional. Jurnal di bidang pengabdian yang semakin banyak maka berdampak terhadap semakin banyak hasil kegiatan pengabdian kepada masyarakat yang akan terpublikasi.

\section{Saran}

Pendampingan mulai dari proses pendirian jurnal, penerbitan, pengusulan akreditasi, dan reakreditasi pada para pengelola jurnal pengabdian harus dilakukan secara berkelanjutan.

\section{E. DAFTAR PUSTAKA}

Adhikara, M. A., Handayani, S., Jumono, S., \& Darmansyah. 2014. Pelatihan Penyusunan Artikel Publikasi Ilmiah pada Mahasiswa Perguruan Tinggi di Jakarta Barat. Jurnal Abdimas, 1 (1), 41-52.

Ananta, H. et al. 2016. Pelatihan dan Pendampingan Penulisan Artikel Ilmiah untuk E-Journal Mahasiswa Jurusan Teknik Elektro FT UNNES. Rekayasa, 14 (2), 121-125.

Ginanjar, A. 2019. Peningkatan Mutu Karya Tulis Dosen FIS dengan Menggunakan Reference Manager Software Mendeley. Harmony, 3 (2), 199-203.

Isa, S., Soewito, B. \& Gunawan, F. 2016. Pengaruh Perangkat Lunak Managemen Referensi Pada Peningkatkan Motivasi Publikasi Para Pendidik. Ethos (Jurnal Penelitian dan Pengabdian Masyarakat), 4 (2), 243-248.

Ismail \& Elihami. 2019. Pelatihan Penyusunan Artikel Publikasi Ilmiah bagi Mahasiswa Perguruan Tinggi STKIP Muhammadiyah Enrekang. Maspul Journal of Community Empowerment, 1 (1), 12-20. 
Jatmiko, W, et al. 2015. Panduan Penulisan Artikel Ilmiah. Jakarta: Fakultas Ilmu Komputer. Universitas Indoensia.

Junandi, S. 2018. Pengelolaan Jurnal Elektronik Bidang Perpustakaan menuju Jurnal Terakreditasi. Pustabiblia: Journal of Library and Information Science, 2(1), 119-136.

Krismayani, I. 2021. Analisis Sitasi Pada Artikel Jurnal Anuva Tahun 2017. ANUVA, 5 (2), 307-314.

Mukhlisah, N., Andi, M., Syarifah, \& Yusri. 2021. Asistensi Pengelolaan Open Journal System (OJS) untuk Mendorong Peningkatan Akreditasi Jurnal Ilmiah dalam Lingkup Universitas Negeri Makassar. Jurnal Hasil Pengabdian Masyarakat, 2(1), 916.

Nafilatur, R., \& Muhammad, H. 2016. Strategi Peningkatan Kemampuan Dosen dalam Penulisan Karya Ilmiah (Studi Multi Kasus pada UNISDA dan STAIDRA di Kabupaten Lamongan). Jurnal Pendidikan, 1(7), 1312-1322.

Rahmawati, C. et al. 2018. Pelatihan Software Mendeley dalam Peningkatan Kualitas Artikel Ilmiah Dosen. Jurnal Pengabdian Kepada masyarakat, 8(1), 30-36.

Ristek-Brin. 2019. Panduan Akreditasi Jurnal Nasional (Arjuna). Direktorat Pengelolaan Kekayaan Intelektual. Direktorat Jenderal Penguatan Riset dan Pengembangan Kementerian Riset dan Teknologi/Badan Riset dan Inovasi Nasional.
Talvin, T. T., \& Widjaja, F. I. 2021.

Pembinaan dan Pelatihan

Penulisan Karya Ilmiah di

Kalangan Dosen Sekolah Tinggi

Teologi Kadesi Yogyakarta.

Yumary: Jurnal Pengabdian

Kepada Masyarakat, 1(3), 127134.

Tundjungsari, V., \& Suhaeri. 2018. Pelatihan Pembuatan Blog untuk Pengembangan Media Pembelajaran di Sekolah Menengah Atas dan Kejuruan. JPP IPTEK, 2 (1), 15-22.

Widoarjo, W., Sutopo, B., Sudaryono, E. A., Syafiqurrahman, M., \& Juliati, J. 2020. Tata Kelola Jurnal Ilmiah dan Strategi Peningkatan Peringkat Akreditasi. Jurnal Pengabdian Masyarakat Kewirausahaan Indonesia (JANAKA), 6 (1).

Yuli, A., \& Sugianti. 2019. Workshop Pembelajaran Teknologi Multimedia untuk Guru SDN 4 Cepoko Kecamatan Ngrayun Guna Pengembangan Bahan Ajar. Jurnal ADIMAS, 46-50. 